\title{
Using Experiential Learning to Improve Student Attitude and Learning Quality in Software Engineering Education
}

Ferdinand Ndifor Che, American University of Nigeria, Yola, Nigeria

(iD) https://orcid.org/0000-0003-4823-2858

Kenneth David Strang, Walden University, USA

iD https://orcid.org/0000-0002-4333-4399

Narasimha Rao Vajjhala, University of New York Tirana, Albania

(iD) https://orcid.org/0000-0002-8260-2392

\begin{abstract}
Experiential learning (EL) has great potential to transform students' learning experiences. Few studies, however, have focused on the use of EL in computer science education. The purpose of this study was to examine students' experiences with EL in computer science. Data were collected to examine the influence of EL on students' attitudes and quality of learning. The antecedent variables included student involvement, learning expectancy, instructor impact, course structure, and prior experience. PLS-SEM with PLSc was used to test generated hypotheses. The findings indicated that student involvement positively correlated with attitudes and learning expectancy. Instructor impact is positively associated with student involvement, quality of learning, and attitudes. Prior experience positively correlated with learning expectancy. Finally, course structure positively moderated the relationship between student involvement and learning expectancy. It is concluded that EL is a promising pedagogy to improve student attitude and quality of learning in software engineering education.
\end{abstract}

\section{KEYWORDS}

Experiential Learning, Instructor Impact, Learning Expectancy, PLS-SEM, Quality of Learning, Software Engineering, Student Attitudes, Student Involvement, Student Perceptions

\section{INTRODUCTION}

Academic leaders in tertiary institutions have wrestled for over two decades with the persistent gap between software engineering education and industry needs. The conventional way of teaching students technical concepts in the classroom does not arm them with the skills that they need to succeed as professionals (Exter, 2014; Garousi, Giray, \& Tuzun, 2019; Garousi, Giray, Tuzun, Catal, \& Felderer, 2020; Hanna, Jaber, Almasalmeh, \& Jaber, 2014; Kövesi \& Csizmadia, 2016; Radermacher \& Walia,

DOI: 10.4018/IJITLHE.20210101.oa2

This article published as an Open Access article distributed under the terms of the Creative Commons Attribution License (http://creativecommons.org/licenses/by/4.0/) which permits unrestricted use, distribution, and production in any medium, provided the author of the original work and original publication source are properly credited. 
2013; SREB.org, 2016; Tuzun, Erdogmus, \& Ozbilgin, 2018). Simultaneously, there is a growing demand for software engineers (Garousi et al., 2020; Tuzun et al., 2018).

Most established universities that offer software engineering as part of their computer science programs offer courses designed to address the problem. Adopting experiential learning (EL) strategies could transform traditional pedagogy into a more learner-centered learning, thereby narrowing the skills gap in software engineering industry (Garousi et al., 2020; Holmes, Allen, \& Craig, 2018; Ng \& Huang, 2013). The EL pedagogy promises significant benefits for students, both academically and professionally, as it facilitates more profound learning, acquiring practical competencies, more engagement, appreciation of diversity, and exposure to professional networking opportunities (Coker \& Porter, 2015; Holmes et al., 2018). Students who have taken an EL course find the overall experience positive - they appreciate the valuable mentorship gained from working on real projects with practical impact (Holmes et al., 2018).

Even though the EL pedagogy is transformative compared to the traditional pedagogy, students can often resist it (Chavan, 2011; Cornell, Johnson, \& Jr, 2013; Hains \& Smith, 2012; Lovelace \& Brickman, 2013). Students are often reluctant to change from a traditional teacher-centered pedagogy that they know and trust (Bedawy, 2017; Hains \& Smith, 2012). In other cases, students perceived the tasks involved as too complicated, or did not feel confident in their ability to complete the tasks, or were merely uncertain about how they would be assessed (Bedawy, 2017; Hains \& Smith, 2012; Leveritt, Ball, \& Desbrow, 2013; Lovelace \& Brickman, 2013; Unda \& Ramos, 2016). In some cases where EL was optional, some students preferred the traditional methods, which were perceived as more predictable (Brennan, 2014). Understanding the factors that lead students to resist EL could provide potential strategies to mitigate such resistance. Whether students have prior experience with a learner-centered course, or whether students perceive the instructor as knowledgeable, competent, and a good mentor could mitigate students' resistance (Hains \& Smith, 2012; Kahu, 2013; Redpath, 2012).

The EL pedagogy inherently incorporates students' involvement as an essential ingredient for achieving learning outcomes (Kahu, 2013). In transitioning to EL, it makes sense to monitor students' perceptions to confirm that attitudes are positive and that such a transformative pedagogy delivers a better quality of learning experience. In addition, quality of learning is a construct that reflects the degree of learning in terms of knowledge and skills gained and the extent to which students are satisfied with the learning process and experience (Thindwa, 2015).

The purpose of this study, therefore, was to examine the factors that would impact students' attitude towards and learning quality of EL activities in a third-year software engineering course. Insights gleaned from the study could help identify promising instructional strategies to improve software engineering students' preparation for future industry careers. The results could also be helpful to other software engineering programs considering introducing EL methods into their curriculum.

\section{LITERATURE REVIEW}

With the traditional teaching approach, often described as the teacher-centered, lecture-based approach, the instructor is actively involved in teaching while the learners are passive, receptive, and mainly listening. The EL approach is learner-centered and deliberately supports the compelling weaving together of educational learning, work, and personal development outcomes (Bavota, Lucia, Fasano, Oliveto, \& Zottoli, 2012; Dragoumanos et al., 2017; Ellis et al., 2015; Holmes et al., 2018; Krutz et al., 2014; Stroulia et al., 2011). The preponderance of evidence in social science research indicates that EL not only improves student's engagement and student's overall performance but narrows the gap between the theoretical concepts taught in the classroom and the skills needed for graduates to succeed once they join the professional workforce (Accenture, 2018; Garousi et al., 2020; Hanna et al., 2014; Ng \& Huang, 2013; Radermacher \& Walia, 2013; Tuzun et al., 2018). Therefore, program designers in many tertiary institutions have explored various strategies to incorporate EL into their programs. 
Student involvement is a critical ingredient for learning. Involvement is a measure of the degree of attention, time, and effort devoted by students to accomplishing learning activities both inside and outside of the classroom (Groccia, 2018; Kuh, 2013; Rangvid, 2018; Woods, Price, \& Crosby, 2019). According to Rangvid (2018), student involvement is a multidimensional construct that captures the degree of engagement, connectedness, commitment, and motivation to learn. Students must engage with the learning process on all levels. Various technologies and active learning methods, mentoring and coaching, can be deployed to improve student involvement and quality of learning (Bhati \& Song, 2019; Lietaert, Roorda, Laevers, Verschueren, \& De Fraine, 2015).

Variables that are relevant to involvement are also included in the study. The Unified Theory of Acceptance and Use of Technology (UTAUT) is often used to study attitude, intention, and behaviour in technology adoption (Alshare \& Lane, 2011; Fauzi, Ali, \& Amirudin, 2019; Sair \& Danish, 2018). In addition, Expectancy Theory is often used to explain how people's anticipation of the desired outcome influences their choices and performance. In this study, learning expectancy relates to a student's expectation that their learning activities' involvement improves their learning quality and performance (Alshare \& Lane, 2011; Shweiki et al., 2015; Unda \& Ramos, 2016). Learning expectancy reflects the notion of perceived ease of use and EL pedagogy's perceived usefulness (Sair \& Danish, 2018). The strength of the association between student involvement and the desired outcome is a measure of motivation reflected in a student's attitude. The introduction of EL was expected to improve students' participation and positively influence students' attitudes toward learning (Coker, Heiser, Taylor, \& Book, 2017; Fauzi et al., 2019; Leal-Rodríguez \& Albort-Morant, 2019; Shweiki et al., 2015). Hence, the following hypotheses were tested, which are also depicted in Figure 1:

Hypothesis 1 (H1): Student involvement in EL positively impacts attitude.

Hypothesis 2 (H2): Student involvement in EL positively impacts the perceived quality of learning. Hypothesis 3 (H3): Student involvement in EL positively impacts perceived learning expectancy. Hypothesis 4 (H4): Learning expectancy positively impacts perceived quality of learning. Hypothesis 5 (H5): Learning expectancy positively impacts attitude.

EL is a learner-centered pedagogy that is informed by the constructivist approach (Allsop, 2016; Bada, 2015; Bose, 2018; Capacho, 2016; Jha, 2017; Kolb \& Kolb, 2018; Passarelli \& Kolb, 2011; Raihan \& Lock, 2012). Through their efforts, the learner constructs knowledge, learning-by-doing as they partake in solving problems, either individually or collaboratively, and critically reflecting on any insights that emerge. The instructor's role is primarily as a coach and mentor. In this study, the instructor's impact was reflected by the degree to which the instructor was perceived as knowledgeable and effective in guiding and facilitating student learning. The instructor was expected to influence students' involvement, attitudes, and quality of learning (Cooper, Ashley, \& Brownell, 2017; Exter, 2014; Fauzi et al., 2019; Fielding-Wells, O’Brien, \& Makar, 2017; Leveritt et al., 2013; Schindler, Burkholder, Morad, \& Marsh, 2017; Shweiki et al., 2015; Unda \& Ramos, 2016). Student's prior experience and the course structure could also influence participation. As such, the following hypotheses were also tested, and were depicted in Figure 1:

Hypothesis 6 (H6): Perceived instructor impact positively impacts student involvement.

Hypothesis 7 (H7): Perceived instructor impact positively impacts the perceived quality of learning.

Hypothesis 8 (H8): Perceived instructor impact positively impacts attitude.

Hypothesis 9 (H9): Perceived impact of course structure positively impacts student involvement.

Hypothesis 10 (H10): Perceived impact of course structure positively impacts perceived learning expectancy.

Hypothesis 11 (H11): Degree of prior experience positively impacts student involvement.

Hypothesis 12 (H12): Degree of prior experience positively impacts perceived learning expectancy. Hypothesis 13 (H13): Degree of prior experience positively impacts perceived learning quality. 
Figure 1. The proposed study model (broken lines signify moderation).

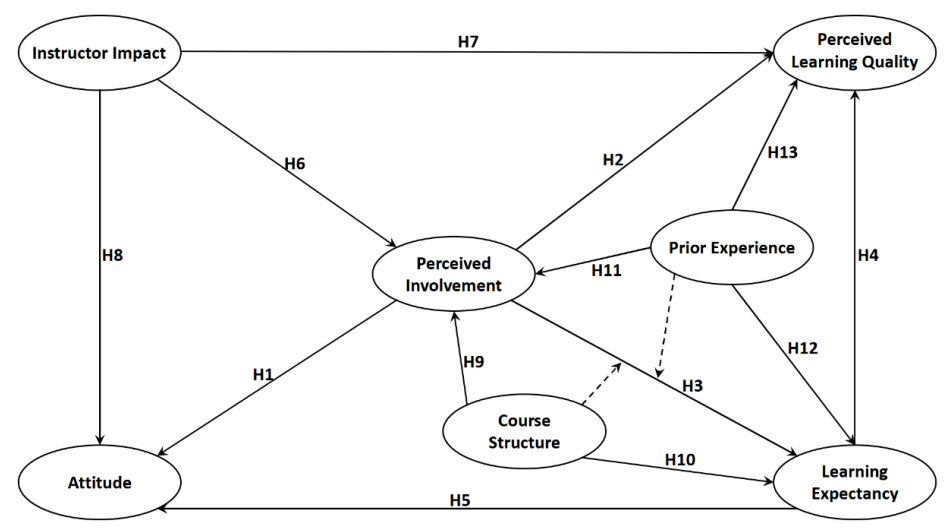

\section{DESIGN OF EL IN SOFTWARE ENGINEERING}

EL in a software engineering course usually implies incorporating various learning-by-doing activities with an emphasis on enriching the students' learning experience in either the engineering or project management aspects or both. These activities include: working on real-world software development projects to gain a deeper understanding of the complexities of the processes involved or the tools and the techniques necessary for developing quality software, and provide an opportunity to develop practical skills as well as real-world exposure to professional collaboration (Dragoumanos, Kakarountas, \& Fourou, 2017; D’Souza \& Rodrigues, 2015; Garousi et al., 2020; Gray \& Christov, 2017a, 2017b; Hanna et al., 2014; Krutz, Malachowsky, \& Reichlmayr, 2014; Ng \& Huang, 2013; Regehr, 2018). Besides, students gain from ongoing mentoring, which is an opportunity to actively reflect on what they are working on, analyze, process, and apply any learnings to improve their deliverables. To get the best out of the experience, students must be actively involved.

Participation is an essential aspect of any course and an even more critical part of an EL course, as was the case in this study. As listed in Table 12 in Appendix A, the structure of the course sessions included two components. Each week's first 90 minutes session was a lecture focused on the theoretical foundations and principles of software engineering. The second 90 minutes session concentrated on EL activities aimed at building on any theoretical foundations earlier introduced. The activities included expectations discussions, tools and environment setup exercises, hands-on practical exercises, a team project, unpacking discussion sessions, and EL assessments. The course syllabus, lecture slides, and supporting materials were organized and provided via a standard Learning Management System (LMS). The course materials and the lectures offered an organized learning experience and as much constructive aligned as possible so that students could readily match expected accomplishments with the corresponding assessment (Lackéus \& Middleton, 2018). Also, independent student-centered learning was supported using a variety of media. The EL sessions involved students working in teams to tackle specific programming challenges, and the instructor acted primarily as a mentor or guide during those sessions. The instructor offered periodic or on-demand unpacking discussion sessions during which individual students or teams met to go over any aspects of the EL activities or even the assessments. The unpacking sessions were completely ungraded, outside of the class sessions, and many students took advantage of these to clarify any areas of ambiguity in the exercises or course materials. Additionally, students used these sessions to explore creative problem-solving ideas. 


\section{METHODOLOGY}

In this study, a quantitative research design was adopted to investigate EL pedagogy's impact on students' attitudes and learning experience. A quantitative approach is useful when exploring the factors that influence an outcome (Creswell, 2013). A questionnaire was designed, pretested on a separate sample of 15 undergraduate software engineering students; minor modifications were made to improve some question-statements perceived as ambiguous before it was administered to the participants via SurveyGizmo in December 2019.

\section{Participants}

The participants in this study were from four cohorts of undergraduate students majoring in software engineering at the American University of Nigeria ("AUN"), Yola, Nigeria. All participants had completed a mandatory third-year software engineering course in computer science unique in Nigeria because AUN programs emphasize critical thinking and problem-solving. The experiential learning pedagogy had been adopted for the course since Spring 2018 and led by the same instructor.

Of the 101 students who had completed the course since Spring 2018 and were invited to participate in the online survey, 76 students $(75 \%)$ responded, nine responses were incomplete and eliminated, resulting in a total valid sample of 67 respondents, a $66 \%$ valid response rate. A response rate of $50 \%$ is considered acceptable for online student learning surveys (Liu \& Wronski, 2018; Petrovčič, Petrič, \& Lozar Manfreda, 2016; Saleh \& Bista, 2017). The respondents' demographic breakdown was male (78\%) and under 25 years $(91 \%)$.

\section{Measures and Procedures}

The main part of the questionnaire was dedicated to information on students' perceptions of their learning experience. The instructor impact, course structure, and prior experience indicators were adapted from a previous study on student learning experiences (Alshare \& Lane, 2011). The EL indicators, which included attitude, student involvement, learning expectancy, and learning quality, were adapted from a previous study on the assessment of EL (De Zan et al., 2015). The participants were asked to respond to question-statements based on a 5-point Likert scale ranging from strongly disagree (1) to strongly agree (5).

\section{Analysis Methods}

A variety of tools and techniques was used to conduct the data analysis. Confirmatory factor analysis (CFA), using parallel analysis with the oblique rotation method, was conducted. The CFA was used to test that the measured perception indicators were consistent with the latent constructs in the developed study model (Alshare \& Lane, 2011; Marsh, Guo, Dicke, Parker, \& Craven, 2020; Marsh, Morin, Parker, \& Kaur, 2014; R Core Team, 2020; Revelle, 2020; RStudio, 2019). The oblique rotation method or "oblimin" was used instead of the traditional "varimax" because of expected correlations between the indicators and factors (Tóth-Király, Bõthe, Rigó, \& Orosz, 2017). The model goodness of fit (GoF) and factor loadings were checked against generally recommended guidelines, and some non-significant factors were dropped (Dvorak, 2017; Kock, 2019; Kock, Avison, \& Malaurent, 2017; Thoma et al., 2018). The model fit indices from the CFA, listed in Table 1, indicated that the model was acceptable for the instructor impact (II) and course structure (CS) factors (Xia \& Yang, 2019). For the student attitude (SA), student involvement (SI), learning expectancy (LE), and quality of learning (QL) factors, the Tucker-Lewis index (TLI) was 0.764 , which is barely acceptable, indicating that the model could be improved. However, because the other indices were acceptable and with the root mean square error of approximation (RMSEA) close to 0.60 (Xia \& Yang, 2019), the model was used with no further improvements.

A partial least squares structural equation modeling (PLS-SEM) analysis of the study path models was conducted with latent variables based on the measured indicators, as listed in Table 2. All latent 
Table 1. Factor loadings from CFA

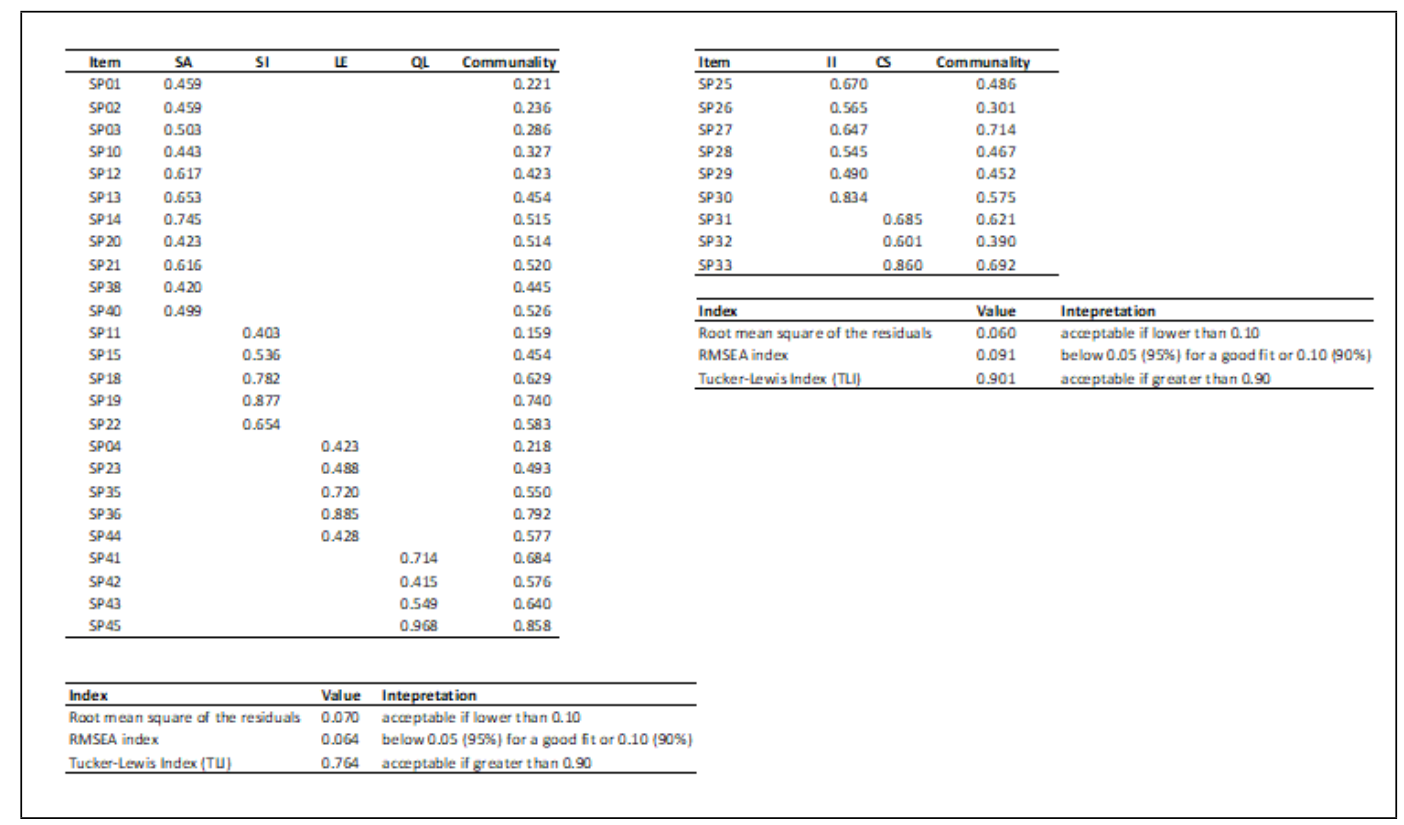

Note. Loadings omitted if less than 0.40

variables were measured reflectively through multiple indicators except the prior experience indicator. WarpPLS 6.0 (Kock, 2017) was used to conduct a robust nonlinear path analysis because it supports the newer consistent PLS (PLSc) technique (Dijkstra \& Henseler, 2015; Kock, 2019). The general WarpPLS model analysis settings selected included the "Factor-Based PLS Type CFM3" option for the outer model analysis algorithm because it relies on Dijkstra's PLSc technique (Dijkstra \& Henseler, 2015). The "Warp3" algorithm was selected for the inner model since it caters to nonlinearity in the latent variable relationships (Kock, 2019). Finally, the "Stable3" resampling method was selected as it generates more stable path coefficients and reliable p-values when the sample size is small $(\mathrm{N}<100)$ (Kock, 2011, 2019).

We relied on the inverse square root method to estimate and validate the study sample size (Kock \& Hadaya, 2018). The analysis confirmed that the sample $(\mathrm{N}=67)$ would result in statistical power equal to or greater than $80 \%$, hence acceptable (Benitez, Henseler, Castillo, \& Schuberth, 2019; Kock \& Hadaya, 2018). Based on expected statistical power estimates, some model paths with low $\beta$ coefficients $(\beta<0.30)$ (Kock et al., 2017) and non-significant paths were removed (Benitez et al., 2019; Hair, Hult, Ringle, \& Sarstedt, 2016; Kock et al., 2017; Kock \& Hadaya, 2018). The final estimated model, in Figure 2, was obtained after dropping all indicators with non-significant loadings (Kock, 2011, 2019), which also corresponded to those indicators with communalities lower than 0.30 in Table 1.

\section{RESULTS}

The final estimated model's assessment in Figure 2 included its overall GoF, quality, or validity of the measurement and structural models, as listed in Table 3. The Tenenhaus GoF, a measure of the model's explanatory power, was 0.553 , indicating that the model had large explanatory power (Kock, 2019). For a good model, the APC, ARS, and AARS indices should be significant at the 5\% level (Kock, 2019). Table 3 shows that all three criteria were met. Similarly, both the AVIF and AFVIF indices, 
Table 2. Latent variables and corresponding indicators

\begin{tabular}{|c|c|c|}
\hline Latent Variable & Indicators & Description \\
\hline Attitude (SA) & $\begin{array}{l}\text { SP01, SP02, SP03, SP10, SP12, SP13, } \\
\text { SP13, SP20, SP21, SP38, SP40 }\end{array}$ & Students' attitudes toward the experiential learning course \\
\hline CrsStruc & SP31, SP32, SP33 & $\begin{array}{l}\text { Students' perception of the impact of the course structure on their } \\
\text { learning - representing whether objectives, expectations, outcomes, } \\
\text { were clearly communicated and well-organized }\end{array}$ \\
\hline Instrimp & SP25, SP26, SP27, SP28, SP29, SP30 & $\begin{array}{l}\text { Students' perceived level of instructor impact on the course - reflecting } \\
\text { the degree to which the instructor was knowledgeable, the instructor's } \\
\text { quality as a guide and mentor in the course }\end{array}$ \\
\hline Exptancy (LE) & SP04, SP23, SP35, SP36, SP44 & $\begin{array}{l}\text { Students' learning expectancy or perception of the ease of use, } \\
\text { perceived usefulness, in relation to the activities or course obligations }\end{array}$ \\
\hline ExpLearn (SI) & SP11, SP15, SP18, SP19, SP22 & $\begin{array}{l}\text { Students' perception of the nature or quality of experiential learning } \\
\text { activities on the course - representing the degree to which they } \\
\text { students perceived their involvement or engagement }\end{array}$ \\
\hline PriorExp & SP34 & $\begin{array}{l}\text { Student's perceived level of background knowledge and programming } \\
\text { experience prior to the course }\end{array}$ \\
\hline QuaLearn (QL) & SP41, SP42, SP43, SP45 & Students' perceived quality of learning or experience \\
\hline
\end{tabular}

which are vertical and full collinearity measures, met the tighter recommended threshold (Kock, 2019). The SPR, which is a measure of the extent to which the model is free of Sympson's paradox, was 1.0, and the related RSCR was 1.0. The SSR, which is a measure of statistical suppression, was also 1.0. Finally, the NLBCDR, which is a measure of the extent to which the bivariate nonlinear coefficients of association support the hypothesized directions of the model's causal links, was 1.0. Therefore, the SPR, RSCR, SSR, NLBCDR were acceptable.

The latent variables' composite reliabilities, which is a measure of the correlation between each latent variable and its construct indicator scores, were estimated. Composite reliability is acceptable if the latent variables' Dijkstra's rho_a is above the recommended threshold of 0.707 (Benitez et al., 2019; Kock, 2014, 2019). Table 4 shows that the composite reliabilities of all latent constructs were above the acceptable threshold, and the construct indicator scores were considered reliable. Convergent validity, a measure of the extent to which the indicators associated with a latent variable measure the same construct, was assessed for the latent variables. Convergent validity is acceptable

Figure 2. Final estimated model, with instructor impact (InstrImp), student involvement (ExpLearn), attitude (Attitude), learning expectancy (Exptancy), quality of learning (QuaLearn), prior experience (PriorExp), and course structure (CrsStruc)

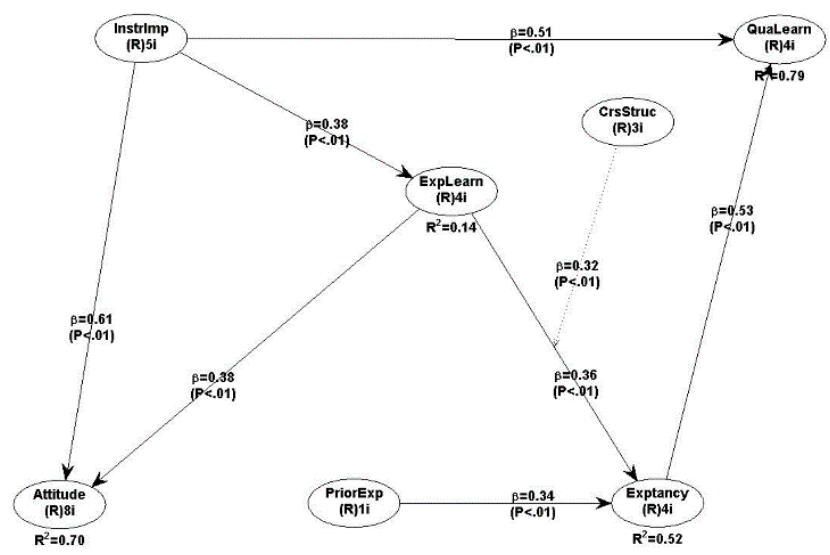


Table 3. Estimated model fit and quality indices

\begin{tabular}{|lcc|}
\hline Index & Value & Interpretation \\
\hline Average path coefficient (APC) & 0.429 & $P<0.001$ \\
Average R-squared (ARS) & 0.539 & $P<0.001$ \\
Average adjusted R-Squared (AARS) & 0.526 & $P<0.001$ \\
Average block VIF (AVIF) & 1.234 & acceptable if $<=5$, ideally $<=3.3$ \\
Average full collinearity VIF (AFVIF) & 2.750 & acceptable if $<=5$, ideally $<=3.3$ \\
Tenenhaus GoF (GoF) & 0.553 small $>=0.1$, medium $>=0.25$, large $>=0.36$ \\
Sympson's paradox ratio (SPR) & 1.000 & acceptable if $>=0.7$, ideally $=1$ \\
R-squared contribution ratio (RSCR) & 1.000 & acceptable if $>=0.9$, ideally $=1$ \\
Statistical suppression ratio (SSR) & 1.000 & acceptable if $>=0.7$ \\
Nonlinear bivariate causality direction ratio (NLBCDR) & 1.000 & acceptable if $>=0.7$ \\
\hline
\end{tabular}

if the p-values associated with the latent variable's indicator loadings are significant at the 5\% level and each of its indicator loadings is equal to or greater than 0.50 (Benitez et al., 2019; Kock, 2014, 2019). Additionally, the average variances extracted (AVE) for each latent variable should be greater than 0.50 (Benitez et al., 2019; Kock, 2019). As seen in Table 4, the convergent reliabilities of all the latent variables were acceptable.

Discriminant validity, a measure of the degree to which a latent variable construct is sufficiently distinct from other latent variables, was also estimated (Hair et al., 2016). It is acceptable if the AVE's square roots for each latent variable are higher than any of its correlations between that latent variable and others (Benitez et al., 2019; Kock, 2019; Kock \& Lynn, 2012). The entries on the diagonal of Table 5 were compared with the entries in the row to the left of and the column below them (Kock, 2019; Kock \& Lynn, 2012). The diagonals' numbers should be higher if there is acceptable discriminant validity (Kock, 2019; Kock \& Lynn, 2012). All latent variables had acceptable discriminant validity except the Attitude variable, indicating a possible collinearity presence in the model (Kock, 2019; Kock \& Lynn, 2012). Variance inflation factor (VIF), a measure of vertical collinearity or collinearity among predictor latent variables in blocks where two or more predictors point at one criterion latent variable are involved, was also estimated. The rule of thumb is that a VIF with a value 3.3 or lower, or more relaxed lower than 5.0, indicates no vertical collinearity in the latent variable block (Kock, 2019; Kock \& Lynn, 2012). As seen in Table 6, all VIFs were below the expected threshold, suggesting no vertical collinearity in the model.

Another type of collinearity, lateral collinearity, a measure of collinearity among indicators of endogenous latent variables, was also estimated. The indicator VIFs, weights, and loadings were examined based on the criteria for acceptable VIFs stated earlier (Kock, 2019; Kock \& Lynn, 2012). Table 4 shows that the measured indicator VIFs are all below the tighter threshold of 3.3. Additionally, almost all of the indicator weights were significant, except some of the Attitude, CrsStruc, and InstrImp indicators. Indicators with non-significant weights and weak effect size $(\mathrm{ES})(\mathrm{ES}<0.02)$ (Benitez et al., 2019; Kock, 2019; Kock \& Lynn, 2012), and if doing so would not compromise construct validity (Kock, 2019; Kock \& Lynn, 2012). A full multicollinearity test was also conducted, and as seen in Table 7, all the latent variables met the more relaxed threshold (VIF $<5.0)$. All the indicator loadings in Table 4 were significant, and that all indicator ES values were above the recommended threshold. Therefore, all the suspect indicators were retained to preserve construct validity (Benitez et al., 2019; Kock, 2019; Kock \& Lynn, 2012), despite the potential presence of lateral collinearity in the model.

Correlation among the latent variable error terms can help establish whether there is a possible existence of hidden confounder(s) or a third variable not represented or captured by the model (Kock, 2019). To rule out any hidden confounders is none of the correlations should be significant at the 5\% level, and the associated VIFs should meet the recommended threshold (Kock, 2019). Table 8 shows 
Table 4. Measurement model evaluation

\begin{tabular}{|c|c|c|c|c|c|c|c|}
\hline Construct/Indicator Code & Dijkstra's $\rho$ & oach's $\alpha$ & AVE & VIF & Weight & Loading & Effect Size \\
\hline Attitude & 0.866 & 0.861 & 0.660 & & & & \\
\hline SP10 & & & & 1.603 & $0.162+$ & $0.566^{* * *}$ & 0.092 \\
\hline SP12 & & & & 1.499 & 0.089 & $0.593^{* * *}$ & 0.053 \\
\hline SP13 & & & & 1.980 & 0.087 & $0.611^{* * *}$ & 0.053 \\
\hline SP14 & & & & 1.779 & $0.191^{*}$ & $0.556^{* * *}$ & 0.106 \\
\hline SP20 & & & & 1.697 & $0.216^{*}$ & $0.750^{* * *}$ & 0.162 \\
\hline SP21 & & & & 2.013 & $0.193^{*}$ & $0.659^{* * *}$ & 0.128 \\
\hline SP38 & & & & 2.093 & 0.067 & $0.745^{* * *}$ & 0.050 \\
\hline SP40 & & & & 2.493 & $0.192^{*}$ & $0.761^{* 6 * 6}$ & 0.146 \\
\hline Crsstruc & 0.790 & 0.787 & 0.744 & & & & \\
\hline SP31 & & & & 1.786 & $0.226^{*}$ & $0.758^{* * *}$ & 0.347 \\
\hline SP32 & & & & 1.471 & 0.096 & $0.706^{* * *}$ & 0.114 \\
\hline SP33 & & & & 1.844 & $0.406^{* * 2 *}$ & $0.768^{* 6 *}$ & 0.203 \\
\hline Instrimp & 0.823 & 0.814 & 0.687 & & & & \\
\hline SP26 & & & & 1.497 & $0.181^{*}$ & $0.590^{* * *}$ & 0.107 \\
\hline SP27 & & & & 2.186 & $0.388^{* * * *}$ & $0.771^{* * *}$ & 0.299 \\
\hline SP28 & & & & 1.810 & 0.092 & $0.614^{* * *}$ & 0.057 \\
\hline SP29 & & & & 1.745 & $0.332^{* *}$ & $0.752^{* * *}$ & 0.250 \\
\hline SP30 & & & & 1.555 & 0.034 & $0.690^{* * *}$ & 0.023 \\
\hline Exptancy & 0.815 & 0.813 & 0.718 & & & & \\
\hline SP23 & & & & 1.672 & $0.226^{\circ}$ & $0.704^{* * *}$ & 0.159 \\
\hline SP35 & & & & 1.920 & 0.096 & $0.687^{* * *}$ & 0.066 \\
\hline SP36 & & & & 2.504 & $0.406^{* 2.8}$ & $0.656^{* 2 *}$ & 0.266 \\
\hline SP44 & & & & 1.517 & $0.243^{*}$ & $0.816^{* * * t}$ & 0.198 \\
\hline Explearn & 0.845 & 0.839 & 0.749 & & & & \\
\hline SP15 & & & & 1.464 & $0.224^{*}$ & $0.754^{* * *}$ & 0.169 \\
\hline SP18 & & & & 2.545 & $0.257^{*}$ & $0.675^{* * *}$ & 0.173 \\
\hline SP19 & & & & 3.004 & $0.241^{*}$ & $0.672^{* * *}$ & 0.162 \\
\hline SP22 & & & & 1.876 & $0.388^{*}$ & $0.875^{* * * *}$ & 0.340 \\
\hline PriorExp & 1.000 & 1.000 & & & & & \\
\hline SP34 & & & & - & $1.000^{* * *}$ & $1.000^{* * *}$ & 1.000 \\
\hline QuaLearn & 0.870 & 0.869 & 0.789 & & & & \\
\hline SP41 & & & & 2.656 & $0.216^{*}$ & $0.802^{* * *}$ & 0.173 \\
\hline SP42 & & & & 1.843 & $0.204^{*}$ & $0.780^{*+8 *}$ & 0.159 \\
\hline SP43 & & & & 1.903 & $0.357^{* * *}$ & $0.827^{* * * *}$ & 0.296 \\
\hline SP45 & & & & 2.626 & $0.24^{*}$ & $0.746^{* * *}$ & 0.179 \\
\hline CrsStruc ExpLearn & 0.890 & 0.884 & 0.621 & & & & \\
\hline SP31^SP15 & & & & 2.922 & $0.172+$ & $0.414^{* * *}$ & 0.071 \\
\hline SP31^SP18 & & & & 4.657 & -0.062 & $0.674^{* * *}$ & 0.042 \\
\hline SP31^SP19 & & & & 10.881 & 0.131 & $0.705^{* * 6}$ & 0.093 \\
\hline$S P 31^{\wedge} S P 22$ & & & & 9.760 & $0.159+$ & $0.629^{* 4 * 6}$ & 0.100 \\
\hline SP32^SP15 & & & & 2.556 & 0.101 & $0.490^{* 6 *}$ & 0.050 \\
\hline SP32^SP18 & & & & 2.590 & $0.150+$ & $0.592^{* * *}$ & 0.089 \\
\hline SP32^SP19 & & & & 6.351 & $0.178^{*}$ & $0.588^{* * *}$ & 0.105 \\
\hline$S P 32^{\wedge} S P 22$ & & & & 5.775 & -0.046 & $0.503^{* * *}$ & 0.023 \\
\hline SP33^SP15 & & & & 3.742 & 0.047 & $0.559^{* * *}$ & 0.026 \\
\hline SP33^SP18 & & & & 5.220 & 0.083 & $0.688^{* * *}$ & 0.057 \\
\hline SP33^SP19 & & & & 7.311 & 0.129 & $0.817^{* * *}$ & 0.106 \\
\hline$S P 33^{\wedge} S P 22$ & & & & 6.281 & $0.294^{*}$ & $0.683^{* 2 *}$ & 0.201 \\
\hline
\end{tabular}


International Journal of Innovative Teaching and Learning in Higher Education

Volume $2 \cdot$ Issue $1 \cdot$ January-March 2021

Table 5. Latent variable correlations and square-roots of AVEs

\begin{tabular}{|c|c|c|c|c|c|c|c|c|}
\hline & Instrimp & Explearn & Exptancy & Qualearn & Attitude & CrsStruc & PriorExp & CrsStruc $^{\wedge}$ Explearn \\
\hline Instrimp & $(0.687)$ & & & & & & & \\
\hline Explearn & 0.359 & (0.749) & & & & & & \\
\hline Exptancy & 0.466 & 0.533 & $(0.718)$ & & & & & \\
\hline Qualearn & 0.742 & 0.536 & 0.754 & (0.789) & & & & \\
\hline Attitude & 0.760 & 0.589 & 0.624 & 0.786 & $(0.660)$ & & & \\
\hline Crsstruc & 0.710 & 0.287 & 0.451 & 0.607 & 0.623 & $(0.744)$ & & \\
\hline PriorExp & 0.057 & -0.192 & 0.222 & 0.217 & 0.011 & 0.056 & $(1.000)$ & \\
\hline $\operatorname{CrsStruc}^{\wedge}$ Explearn & 0.033 & 0.215 & 0.108 & 0.079 & 0.042 & 0.046 & -0.178 & $(0.621)$ \\
\hline
\end{tabular}

Note. Square roots of AVEs are shown on the diagonal, within parentheses.

Table 6. Vertical collinearity estimates

\begin{tabular}{|c|c|c|c|c|c|c|c|c|}
\hline & Instrimp & Explearn & Exptancy & Qualearn & Attitude & CrsStruc & PriorExp & CrsStruc $^{\wedge}$ Explearn \\
\hline Exptancy & & 1.319 & & & & & 1.030 & 1.351 \\
\hline Qualearn & 1.279 & & 1.279 & & & & & \\
\hline Attitude & 1.190 & 1.190 & & & & & & \\
\hline
\end{tabular}

Note. VIFs for each predictor (column) with reference to a criterion latent variable (rows).

Table 7. Estimated latent variable coefficients

\begin{tabular}{|rrrccccc|}
\hline Variable & R-squared & Adj. R-squared & Cronbach's $\alpha$ & Dijkstra's $\rho$ & AVE & Full Collin. VIF & Q-squared \\
\hline Instrimp & & & 0.814 & 0.823 & 0.814 & 3.652 & 0.224 \\
Explearn & 0.142 & 0.129 & 0.839 & 0.845 & 0.839 & 2.034 & 0.566 \\
Exptancy & 0.523 & 0.501 & 0.813 & 0.815 & 0.813 & 2.713 & 0.791 \\
QuaLearn & 0.786 & 0.780 & 0.869 & 0.870 & 0.869 & 5.025 & 0.713 \\
Attitude & 0.703 & 0.693 & 0.861 & 0.866 & 0.861 & 3.978 & \\
CrsStruc & & & 0.787 & 0.790 & 0.787 & 2.143 & 1.358 \\
PriorExp & & & 1.000 & 1.000 & 1.000 & 1.095 \\
CrsStruc^Explearn & & & 0.884 & 0.890 & 0.884 & \\
\hline
\end{tabular}

Table 8. Correlations among latent variable error terms, associated VIFs (on diagonal)

\begin{tabular}{|c|c|c|c|c|c|}
\hline & Instrlmp & Explearn & Exptancy & QuaLearn & Attitude \\
\hline \multicolumn{6}{|l|}{ InstrImp } \\
\hline ExpLearn & & (1.041) & & & \\
\hline Exptancy & & -0.044 & $(1.070)$ & & \\
\hline Qualearn & & 0.194 & -0.082 & $(1.102)$ & \\
\hline Attitude & & 0.010 & 0.220 & 0.203 & (1.109) \\
\hline \multicolumn{6}{|l|}{ Crsstruc } \\
\hline PriorExp & & & & & \\
\hline
\end{tabular}

Note: $\uparrow p<0.10,{ }^{*} p<0.05$ for the error term correlations. 
that none of the error term correlations were significant, and all the VIFs met the recommended threshold, suggesting that there were no evident hidden confounders in the model.

The Stone-Geisser or Q-squared coefficient is a non-parametric measure of each predictor latent variable's predictive validity or relevance through an endogenous criterion latent variable in a latent variable block (Kock, 2019). Acceptable predictive validity should be greater than zero (Kock, 2019). Table 7 shows that all the relevant latent variable blocks met the criteria, indicating acceptable model predictive validity.

\section{Evaluating the Path Coefficients and Hypotheses}

The estimated model path coefficients generated by WarpPLS are standardized regression coefficients. Each path coefficient indicates that if the independent latent variable changes by one standard unit, when all other explanatory constructs are kept constant, then the dependent latent variable can be expected to change by the coefficient amount (Benitez et al., 2019; Kock, 2019). Additionally, the effect size of any significant relationship between constructs should be investigated to establish its practical significance (Benitez et al., 2019; Kock, 2019; Kock \& Hadaya, 2018; Marsh et al., 2020, 2014). The effect size is a measure of the magnitude of an effect, independent of sample size. The effect size should range from 0.020 to 0.150 (weak effect), 0.150 to 0.350 (medium), or equal to or larger than 0.350 (large) (Benitez et al., 2019; Hair et al., 2016; Kock, 2019; Kock \& Hadaya, 2018; Marsh et al., 2020, 2014; Tóth-Király et al., 2017). Table 9 shows that the estimated model's effect sizes ranged from 0.142 (weak) to 0.465 (large).

\section{Table 9. Path coefficients and effect sizes}

\begin{tabular}{|c|c|c|}
\hline \multirow{2}{*}{$\begin{array}{l}\text { Relationship } \\
\text { Students' perceived involvement } \rightarrow>\text { Students' attitudes }(\mathrm{H} 1)\end{array}$} & \multicolumn{2}{|c|}{ Coefficient Effect Size } \\
\hline & $0.380^{* 6 *}$ & 0.237 \\
\hline \multicolumn{3}{|l|}{ Students' perceived involvement $->$ Perceived quality of learning $(\mathrm{H} 2)$} \\
\hline Students' perceived involvement $->>$ Students' learning expectancy $(\mathrm{H} 3)$ & $0.359 * *$ & 0.196 \\
\hline Students' learning expectancy -> Perceived quality of learning $(\mathrm{H} 4)$ & $0.527^{* * *}$ & 0.402 \\
\hline \multicolumn{3}{|l|}{ Students' learning expectancy -> Students' attitudes (H5) } \\
\hline Students' perceived level of instructor impact $-\rightarrow$ Students' perceived involvement $(\mathrm{H} 6)$ & $0.377^{* * *}$ & 0.142 \\
\hline Students' perceived level of instructor impact -->Perceived quality of learning $(\mathrm{H} 7)$ & $0.509^{* * *}$ & 0.384 \\
\hline Students' perceived level of instructor impact --> Students' attitudes (H8) & $0.610^{* * *}$ & 0.465 \\
\hline \multicolumn{3}{|l|}{ Students' perceived impact of course structure --> Students' perceived involvement (H9) } \\
\hline \multicolumn{3}{|l|}{ Students' perceived impact of course structure --> Perceived quality of expectancy (H10) } \\
\hline \multicolumn{3}{|l|}{ Students' degree of prior experience --> Students' perceived involvement (H11) } \\
\hline Students' degree of prior experience --> Students' learning expectancy $(\mathrm{H} 12)$ & $0.344^{* * *}$ & 0.147 \\
\hline Students' degree of prior experience --> Perceived quality of learning (H13) & & \\
\hline Students' perceived impact of course structure --> Students' learning expectancy (moderating) & $0.324^{* *}$ & 0.181 \\
\hline
\end{tabular}

Note: $\uparrow p<0.10,{ }^{*} p<0.05,{ }^{* *} p<0.01,{ }^{* * *} p<0.001$, one-tailed test.

Furthermore, the coefficient of determination (R-squared) is often used in ordinary least square regression to indicate the proportion of variance in the dependent construct explained by the model (Benitez et al., 2019; Kock, 2019; Kock \& Lynn, 2012). It is a measure of the model's in-sample predictive power in PLS-SEM (Benitez et al., 2019; Kock, 2019; Marsh et al., 2020). Figure 2 and Table 7 show that the construct R-squared values ranged from 0.142 (ExpLearn) to 0.703 (Attitude). The R-squared value for the student involvement construct was very small. Still, it was impossible to establish whether there was cause for concern because other comparable empirical studies on EL were not found. 
Table 10. Estimated total effects with associated path coefficients and (number of paths, effect size)

\begin{tabular}{|c|c|c|c|c|c|}
\hline & Instrimp & Explearn & Exptancy & PriorExp & CrsStruc^ExpLearn \\
\hline \multicolumn{6}{|c|}{ Instrimp } \\
\hline \multicolumn{6}{|c|}{ ExpLearn $0.377^{* * *}(1,0.142)$} \\
\hline Exptancy & $0.136^{*}(1,0.063)$ & $0.359^{* * *}(1,0.196)$ & & $0.344^{* * *}(1,0.147)$ & $0.324^{* *}(1,0.181)$ \\
\hline Qualearn & $0.580^{* * *}(2,0.438)$ & $0.189^{*}(1,0.101)$ & $0.527^{* * *}(1,0.402)$ & $0.181 *(1,0.039)$ & $0.170^{*}(1,0.013)$ \\
\hline Attitude & $0.754^{* * *}(2,0.575)$ & $0.380^{* * *}(1,0.237)$ & & & \\
\hline
\end{tabular}

Note: $\uparrow p<0.10,{ }^{*} p<0.05,{ }^{* *} p<0.01,{ }^{* * *} p<0.001$.

Table 11. Summary evaluation of hypotheses

\begin{tabular}{|cc|}
\hline Hypothesis & Supported \\
\hline Students' perceived involvement --> Students' attitudes (H1) & Yes \\
Students' perceived involvement --> Perceived quality of learning (H2) & No \\
Students' perceived involvement --> Students' learning expectancy (H3) & Yes \\
Students' learning expectancy -> Perceived quality of learning (H4) & Yes \\
Students' learning expectancy -> Students' attitudes (H5) & No \\
Students' perceived level of instructor impact -> Students' perceived involvement (H6) & Yes \\
Students' perceived level of instructor impact -->Perceived quality of learning (H7) & Yes \\
Students' perceived level of instructor impact -> Students' attitudes (H8) & Yes \\
Students' perceived impact of course structure --> Students' perceived involvement (H9) & No \\
Students' perceived impact of course structure --> Perceived quality of expectancy (H10) & No \\
Students' degree of prior experience -> Students' perceived involvement (H11) & No \\
Students' degree of prior experience --> Students' learning expectancy (H12) & Yes \\
Students' degree of prior experience --> Perceived quality of learning (H13) & No \\
Students' perceived impact of course structure --> Students' learning expectancy (moderating) & Yes \\
\hline
\end{tabular}

As listed in Table 3, the model explained 53\% (AARS=52.6) of the variation in the study outcomes of quality of learning and attitudes. Figure 2 and Table 7 also show that the instructor impact and learning expectancy explained $78.6 \%$ of the variation in learning quality. Similarly, instructor impact and student involvement explained $70.3 \%$ of the variation in attitudes and only $14.2 \%$ for student involvement. Finally, student involvement and prior experience explained $52.3 \%$ of the variation in learning expectancy.

All the path coefficients in the final model were significant at the 5\% level, as seen in Figure 2 and Table 9. Figure 2 and Table 11 show that several of the hypothesized relationships were significant at the 5\% level and supported. Instructor impact positively correlated with quality of learning $(\beta=0.580$, $\mathrm{P}<0.001)$, student involvement $(\beta=0.377, \mathrm{P}<0.001)$, and attitudes $(\beta=0.754, \mathrm{P}<0.001)$. Student involvement positively correlated with attitude $(\beta=0.380, \mathrm{P}<0.001)$, learning expectancy $(\beta=0.359$, $\mathrm{P}<0.001)$, but only indirectly with quality of learning $(\beta=0.189, \mathrm{P}<0.011)$ through learning expectancy. Similarly, learning expectancy positively correlated with quality of learning $(\beta=0.527, \mathrm{P}<0.001)$ but not attitude. Instructor impact positively correlated with student involvement $(\beta=0.377, \mathrm{P}<0.001)$, quality of learning $(\beta=0.509, \mathrm{P}<0.001)$, and attitude $(\beta=0.610, \mathrm{P}<0.001)$. Instructor impact also positively correlated indirectly with attitudes $(\beta=0.144, \mathrm{P}<0.043)$, learning expectancy $(\beta=0.136$, $\mathrm{P}<0.053)$, but not quality of learning $(\beta=0.071, \mathrm{P}<0.152)$. Therefore, any indirect effect on the quality of learning was solely because of student involvement. Prior experience positively correlated 
with learning expectancy $(\beta=0.344, \mathrm{P}<0.001)$ but nothing else. Finally, course structure positively moderated the student involvement relationship with learning expectancy $(\beta=0.324, \mathrm{P}<0.002)$.

Concerning the association involving attitudes, instructor impact had a much stronger effect than student involvement based on the path coefficients, as seen in Figure 2 and Table 10. For the association with quality of learning, instructor impact, and learning expectancy were almost equally impactful. For the association with learning expectancy, both student involvement and prior experience had an almost equal impact. Interestingly, instructor impact had a relatively moderate effect on student involvement. Given the relatively small coefficient of determination on student involvement (R-squared $=0.142$ ), this may indicate that additional factors, not accounted for, influence student involvement. However, no comparable empirical studies could be found to make a considered assessment as to whether there was cause for concern.

\section{DISCUSSION}

As shown in the above section, a statistically significant SEM was fitted to survey the data, demonstrating that student involvement in EL was positively associated with attitude and quality of learning in an undergraduate software engineering course $(n=67)$. The final model had a GoF of $55 \%$ and good explanatory power $\left(\mathrm{R}^{2}=0.526, \mathrm{P}<0.05\right)$. In the model, instructor impact had the most significant overall influence on student attitude with a large effect size $(\mathrm{ES}=0.575)$. The instructor impact also significantly influenced the quality of learning with a large effect size $(\mathrm{ES}=0.438)$. The instructor impact had a significant influence on student involvement with a small effect size $(\mathrm{ES}=0.142$ ). Student involvement had a significant influence on learning expectancy with a small effect size (ES=0.196). Student involvement also had a significant impact on student attitude with a moderate effect size $(\mathrm{ES}=0.237)$. Finally, learning expectancy significantly influenced the quality of learning with a large effect size $(\mathrm{ES}=0.402)$. These results corroborated other findings in the extant literature, which suggest that student attitude, involvement, and learning experience improve when the EL pedagogy is adopted (Lackéus \& Middleton, 2018).

Interestingly, the course structure had a significant influence only as a moderator in the relationship between student involvement and learning expectancy $(\beta=0.324, \mathrm{P}<0.05)$, with a moderate effect size $(\mathrm{ES}=0.181$ ). This moderator represented the conditional association of course structure on learning expectancy and could indicate that a proportion of the students felt that the course design helped them learn, potentially reducing complexity or providing an easy to follow roadmap. However, another factor that could also account for this result was prior experience, which had a significant influence on learning expectancy $(\beta=0.344, \mathrm{P}<0.05)$ with a moderate effect size $(\mathrm{ES}=0.147)$. Coincidently, prior experience did not significantly associate with other hypothesized factors such as student involvement or quality of learning. There were also mixed findings in the literature concerning the impact of prior experience on EL perceptions. Some researchers claimed that prior experience could influence learning expectancy, whereas others asserted that there could be moderating relationships from prior experience to other factors, including learning expectancy (Cooper et al., 2017; Fauzi et al., 2019; Fielding-Wells et al., 2017; Shweiki et al., 2015; Unda \& Ramos, 2016). In this study, prior experience could have been preconditioned by student exposure with the same instructor from other computer science courses or the instructors being well-recognized and highly regarded across the university. Surprisingly, student involvement had only a small indirect effect on the quality of learning $(\beta=0.189, \mathrm{P}<0.05)$ with a weak effect size $(\mathrm{ES}=0.101)$. The lack of a direct relationship between student involvement and quality of learning could reflect some confusion within the survey items where quality of learning may have been perceived as driven by the instructor and thus associated with the instructor factor instead. Nevertheless, this finding was consistent with the a priori literature in as far as student involvement should relate to student attitude and learning expectancy but not directly to learning quality (Alkan, 2016; Armbruster et al., 2009; Bruegge et al., 2015). Other similar future 
studies with larger samples in other higher education institutions may provide additional evidence or confirmation of the findings of this study.

\section{CONCLUSION}

A review of the relevant literature revealed that $\mathrm{EL}$ is a transformative pedagogy that promises student engagement and performance improvements. However, few empirical studies have examined how computer science students perceive learner-centered pedagogy in higher education institutions. In this study, EL was empirically examined within the context of an undergraduate soft engineering course. A statistically robust set of techniques was applied to test the hypotheses, using CFA and then PLSSEM with consistent partial least squares (PLSc) for the study model's path analysis. As revealed and confirmed by the results, EL is a promising instructional technique that has the great potential to enhance student attitude and learning quality in software engineering education.

\section{ACKNOWLEDGMENT}

The authors would like to express their special thanks to all students who participated in the survey. 


\section{REFERENCES}

Accenture. (2018). Bridging the skills gap in the future workforce. Accenture. https://www.accenture.com/

Alkan, F. (2016). Experiential learning: Its effects on achievement and scientific process skills. Journal of Turkish Science Education, 13(2), 15-26. doi:10.12973/tused.10164a

Allsop, Y. (2016, November 1). Does technology improve learning - the value of constructivist approaches to technology-based learning? ICT in Practice. http://www.ictinpractice.com/does-technology-improve-learningthe-value-of-constructivist-approaches-to-technology-based-learning/

Alshare, K. A., \& Lane, P. (2011). Predicting student-perceived learning outcomes and satisfaction in ERP courses: An empirical investigation. Communications of the Association for Information Systems, 28(34), 571-584. doi:10.17705/1CAIS.02834

Armbruster, P., Patel, M., Johnson, E., \& Weiss, M. (2009). Active learning and student-centered pedagogy improve student attitudes and performance in introductory biology. CBE Life Sciences Education, 8(3), $203-213$. doi:10.1187/cbe.09-03-0025 PMID:19723815

Bada, S. O. (2015). Constructivism learning theory: A paradigm for teaching and learning. IOSR Journal of Research \& Method in Education, 5(6), 66-70. doi:10.9790/7388-05616670

Bansal, P. (2014). Effects of experiential learning strategies on problem solving ability of adolescents from psychological hardiness perspective. Indian Journal of Health \& Wellbeing, 5(5), 574-578. doi:10.1037/ e682942012-083

Bavota, G., Lucia, A. D., Fasano, F., Oliveto, R., \& Zottoli, C. (2012). Teaching software engineering and software project management: An integrated and practical approach. 2012 34th International Conference on Software Engineering (ICSE), 1155-1164. doi:10.1109/ICSE.2012.6227027

Bedawy, R. E. (2017). Experiential learning for supporting learning effectiveness in business education: A case study from Egypt. International Journal of Business and Management, 12(5), 159-176. doi:10.5539/ijbm. v12n5p159

Benitez, J., Henseler, J., Castillo, A., \& Schuberth, F. (2019). How to perform and report an impactful analysis using partial least squares: Guidelines for confirmatory and explanatory IS research. Information \& Management, 103168. Advance online publication. doi:10.1016/j.im.2019.05.003

Bhati, A., \& Song, I. (2019). New methods for collaborative experiential learning to provide personalised formative assessment. International Journal of Emerging Technologies in Learning, 14(07), 179-195. doi:10.3991/ijet. v14i07.9173

Bose, S. (2018). Unit-3 Learning Theories: Implications for ICT. Indira Gandhi National Open University http:// egyankosh.ac.in/bitstream/123456789/46298/1/Unit-3.pdf

Brennan, R. (2014). Reflecting on experiential learning in marketing education. The Marketing Review, 14(1), 97-108. doi:10.1362/146934714X13948909473266

Bruegge, B., Krusche, S., \& Alperowitz, L. (2015). Software engineering project courses with industrial clients. ACM Transactions on Computing Education, 15(4), 17.1-17.31. 10.1145/2732155

Capacho, J. (2016). Teaching and learning methodologies supported by ICT applied in computer science. Turkish Online Journal of Distance Education, 17(2), 59-73. doi:10.17718/tojde.48315

Chavan, M. (2011). Higher education students' attitudes towards experiential learning in international business. Journal of Teaching in International Business, 22(2), 126-143. doi:10.1080/08975930.2011.615677

Coker, J. S., Heiser, E., Taylor, L., \& Book, C. (2017). Impacts of experiential learning depth and breadth on student outcomes. Journal of Experiential Education, 40(1), 5-23. doi:10.1177/1053825916678265

Cooper, K. M., Ashley, M., \& Brownell, S. E. (2017). Using expectancy value theory as a framework to reduce student resistance to active learning: A proof of concept. Journal of Microbiology \& Biology Education, 18(2). Advance online publication. doi:10.1128/jmbe.v18i2.1289 PMID:28861130 
Cornell, R. M., Johnson, C. B., \& Jr, W. C. S. (2013). Enhancing student experiential learning with structured interviews. Journal of Education for Business, 88(3), 136-146. doi:10.1080/08832323.2012.659296

Creswell, J. W. (2013). Educational research: Planning, conducting, and evaluating quantitative and qualitative research (4th ed.). Pearson.

D'Souza, M. J., \& Rodrigues, P. (2015). Extreme pedagogy: An agile teaching-learning methodology for engineering education. Indian Journal of Science and Technology, 8(9), 828. doi:10.17485/ijst/2015/v8i9/53274

Dijkstra, T. K., \& Henseler, J. (2015). Consistent partial least squares path modeling. Management Information Systems Quarterly, 39(2), 297-316. doi:10.25300/MISQ/2015/39.2.02

Dragoumanos, S., Kakarountas, A., \& Fourou, T. (2017). Young technology entrepreneurship enhancement based on an alternative approach of project-based learning. 2017 IEEE Global Engineering Education Conference (EDUCON), 351-358. doi:10.1109/EDUCON.2017.7942872

Dvorak, D. (2017, October 20). The 4 factors of learning-Knowledge, attitudes, skills, and habits (KASH). The \#1 Motivational Guide. http://blog.dougdvorak.com/the-4-factors-of-learning/

Ellis, H. J. C., Hislop, G. W., Jackson, S., \& Postner, L. (2015). Team project experiences in humanitarian free and open source software (HFOSS). ACM Transactions on Computing Education, 15(4), 1-23. Advance online publication. doi:10.1145/2684812

Exter, M. (2014). Comparing educational experiences and on-the-job needs of educational software designers. Proceedings of the 45th ACM Technical Symposium on Computer Science Education, 355-360. doi: $10.1145 / 2538862.2538970$

Fauzi, A. F. A. A., Ali, K. N., \& Amirudin, R. (2019). Evaluating students readiness, expectancy, acceptance and effectiveness of augmented reality based construction technology education. International Journal of Built Environment and Sustainability, 6(1), 7-13. doi:10.11113/ijbes.v6.n1.309

Fede, J. H., Gorman, K. S., \& Cimini, M. E. (2018). Student employment as a model for experiential learning. Journal of Experiential Education, 41(1), 107-124. doi:10.1177/1053825917747902

Fielding-Wells, J., O'Brien, M., \& Makar, K. (2017). Using expectancy-value theory to explore aspects of motivation and engagement in inquiry-based learning in primary mathematics. Mathematics Education Research Journal, 29(2), 237-254. Advance online publication. doi:10.1007/s13394-017-0201-y

Garousi, V., Giray, G., \& Tuzun, E. (2019). Understanding the knowledge gaps of software engineers: An empirical analysis based on SWEBOK. ACM Transactions on Computing Education, 20(1), 3.1-3.33. 10.1145/3360497

Garousi, V., Giray, G., Tuzun, E., Catal, C., \& Felderer, M. (2020). Closing the gap between software engineering education and industrial needs. IEEE Software, 37(2), 68-77. doi:10.1109/MS.2018.2880823

Gray, M. B., \& Christov, S. C. (2017). An innovative approach to experiential education and interprofessional collaboration between nursing and software engineering: CIN: Computers, Informatics. Nursing, 35(4), 169-173. doi:10.1097/CIN.0000000000000352 PMID:28362685

Groccia, J. E. (2018). What is student engagement? New Directions for Teaching and Learning, 2018(154), 11-20. doi:10.1002/t1.20287

Hains, B. J., \& Smith, B. (2012). Student-centered course design: Empowering students to become self-directed learners. Journal of Experiential Education, 35(2), 357-374. doi:10.1177/105382591203500206

Hair, J., Hult, G. T. M., Ringle, C. M., \& Sarstedt, M. (2016). A primer on partial least squares structural equation modeling ( $2 \mathrm{nd}$ ed.). SAGE.

Hanna, S., Jaber, H., Almasalmeh, A., \& Jaber, F. A. (2014). Reducing the gap between software engineering curricula and software industry in Jordan. Journal of Software Engineering and Applications, 7(7), 602-616. doi:10.4236/jsea.2014.77056

Holmes, R., Allen, M., \& Craig, M. (2018). Dimensions of experientialism for software engineering education. Proceedings of the 40th International Conference on Software Engineering Software Engineering Education and Training - ICSE-SEET '18, (pp. 31-39). Gothenburg, Sweden: ACM Press. doi:10.1145/3183377.3183380 
Jha, A. (2017). ICT pedagogy in higher education: A constructivist approach. Journal of Training and Development, 3, 64-70. doi:10.3126/jtd.v3i0.18232

Kahu, E. R. (2013). Framing student engagement in higher education. Studies in Higher Education, 38(5), 758-773. doi:10.1080/03075079.2011.598505

Kock, N. (2011). Using WarpPLS in e-collaboration studies: Mediating effects, control and second order variables, and algorithm choices. International Journal of e-Collaboration, 7(3), 1-13. doi:10.4018/jec.2011070101

Kock, N. (2014). Advanced mediating effects tests, multi-group analyses, and measurement model assessments in PLS-based SEM. International Journal of e-Collaboration, 10(1), 1-13. doi:10.4018/ijec.2014010101

Kock, N. (2017). WarpPLS (Version 6.0). ScriptWarp Systems. http://www.warppls.com/

Kock, N. (2019). WarpPLS 6.0 user manual. ScriptWarp Systems. https://www.scriptwarp.com/warppls/ UserManual_v_6_0.pdf

Kock, N., Avison, D., \& Malaurent, J. (2017). Positivist information systems action research: Methodological issues. Journal of Management Information Systems, 34(3), 754-767. doi:10.1080/07421222.2017.1373007

Kock, N., \& Hadaya, P. (2018). Minimum sample size estimation in PLS-SEM: The inverse square root and gamma-exponential methods. Information Systems Journal, 28(1), 227-261. doi:10.1111/isj.12131

Kock, N., \& Lynn, G. (2012). Lateral collinearity and misleading results in variance-based SEM: An illustration and recommendations. Journal of the Association for Information Systems, 13(7), 546-580. Advance online publication. doi:10.17705/1jais.00302

Kolb, A., \& Kolb, D. (2018). Eight important things to know about the experiential learning cycle. Australian Educational Leader, 40(3). https://learningfromexperience.com/downloads/research-library/eight-importantthings-to-know-about-the-experiential-learning-cycle.pdf

Kövesi, K., \& Csizmadia, P. (2016). Industry perception of new engineering graduates: The gap between requirements and reality. 44th SEFI Conference, 11. http://sefibenvwh.cluster023.hosting.ovh.net/wp-content/ uploads/2017/09/kovesi-industry-perception-of-engineering-graduates-152_a.pdf

Krutz, D. E., Malachowsky, S. A., \& Reichlmayr, T. (2014). Using a real world project in a software testing course. In Proceedings of the 45th ACM Technical Symposium on Computer Science Education, (pp. 49-54). Atlanta, GA: Association for Computing Machinery. doi:10.1145/2538862.2538955

Kuh, G. D. (2013). What matters to student success: The promise of high-impact practices. National Institute for Learning Outcomes Assessment: Making Learning Outcomes Usable \& Transparent, 48.

Lackéus, M., \& Middleton, K. W. (2018). Assessing experiential entrepreneurship education: Key insights from five methods in use at a venture creation programme. In Experiential Learning for Entrepreneurship Theoretical and Practical Perspectives on Enterprise Education (pp. 19-50). doi:10.1007/978-3-319-90005-6_2

Leal-Rodríguez, A. L., \& Albort-Morant, G. (2019). Promoting innovative experiential learning practices to improve academic performance: Empirical evidence from a Spanish Business School. Journal of Innovation \& Knowledge, 4(2), 97-103. doi:10.1016/j.jik.2017.12.001

Leveritt, M., Ball, L., \& Desbrow, J. (2013). Students' perceptions of an experiential learning activity designed to develop knowledge of food and food preparation methods. Journal of Food Science Education, 12(3), 56-60. doi:10.1111/1541-4329.12009

Lietaert, S., Roorda, D., Laevers, F., Verschueren, K., \& De Fraine, B. (2015). The gender gap in student engagement: The role of teachers' autonomy support, structure, and involvement. The British Journal of Educational Psychology, 85(4), 498-518. doi:10.1111/bjep.12095 PMID:26446905

Liu, M., \& Wronski, L. (2018). Examining completion rates in web surveys via over 25,000 real-world surveys. Social Science Computer Review, 36(1), 116-124. doi:10.1177/0894439317695581

Lovelace, M., \& Brickman, P. (2013). Best practices for measuring students' attitudes toward learning science. CBE Life Sciences Education, 12(4), 606-617. doi:10.1187/cbe.12-11-0197 PMID:24297288 
Marsh, H. W., Guo, J., Dicke, T., Parker, P. D., \& Craven, R. G. (2020). Confirmatory factor analysis (CFA), exploratory structural equation modeling (ESEM), and Set-ESEM: Optimal balance between goodness of fit and parsimony. Multivariate Behavioral Research, 55(1), 102-119. doi:10.1080/00273171.2019.1602503 PMID:31204844

Marsh, H. W., Morin, A. J. S., Parker, P. D., \& Kaur, G. (2014). Exploratory structural equation modeling: An integration of the best features of exploratory and confirmatory factor analysis. Annual Review of Clinical Psychology, 10(1), 85-110. doi:10.1146/annurev-clinpsy-032813-153700 PMID:24313568

Mourshed, M., Farrell, D., \& Barton, D. (2012). Education to employment: Designing a system that works. https://www.mckinsey.com/ /media/McKinsey/Industries/Social\%20Sector/Our\%20Insights/Education\%20 to $\% 20$ employment $\% 20$ Designing $\% 20 \mathrm{a} \% 20$ system $\% 20$ that $\% 20$ works/Education $\% 20$ to $\% 20$ employment $\% 20$ designing $\% 20 \mathrm{a} \% 20$ system $\% 20$ that $\% 20$ works.ashx

Neyem, A., Benedetto, J. I., \& Chacon, A. F. (2014). Improving software engineering education through an empirical approach: Lessons learned from capstone teaching experiences. In Proceedings of the 45th ACM Technical Symposium on Computer Science Education, (pp. 391-396). Atlanta, GA: Association for Computing Machinery. doi:10.1145/2538862.2538920

Ng, P.-W., \& Huang, S. (2013). Essence: A framework to help bridge the gap between software engineering education and industry needs. 2013 26th International Conference on Software Engineering Education and Training (CSEE T), 304-308. doi:10.1109/CSEET.2013.6595266

OECD. (2018). The future of education and skills: Education 2030 (Position Paper No. E2030; p. 23). 2 rue André Pascal - 75775 Paris Cedex 16-France: The Organisation for Economic Co-operation and Development (OECD). https://www.oecd.org/education/2030/E2030\%20Position\%20Paper\%20(05.04.2018).pdf

Passarelli, A. M., \& Kolb, D. A. (2011). Using experiential learning theory to promote student learning and development. https://weatherhead.case.edu/departments/organizational-behavior/workingPapers/WP-11-03.pdf

Petrovčič, A., Petrič, G., \& Lozar Manfreda, K. (2016). The effect of email invitation elements on response rate in a web survey within an online community. Computers in Human Behavior, 56(C), 320-329. doi:10.1016/j. chb.2015.11.025

R Core Team. (2020). R: A language and environment for statistical computing. https://www.r-project.org/

Radermacher, A., \& Walia, G. (2013). Gaps between industry expectations and the abilities of graduates. In Proceeding of the 44th ACM Technical Symposium on Computer Science Education, (pp. 525-530). Denver, CO: Association for Computing Machinery. doi:10.1145/2445196.2445351

Raihan, A., \& Lock, S. (2012). Technology integration for meaningful learning-The constructivist view. Academic Press.

Rangvid, B. S. (2018). Student engagement in inclusive classrooms. Education Economics, 26(3), 266-284. do i: $10.1080 / 09645292.2018 .1426733$

Redpath, L. (2012). Confronting the bias against on-line learning in management education. Academy of Management Learning \& Education, 11(1), 125-140. doi:10.5465/amle.2010.0044

Regehr, J. (2018, January 23). A conversation about teaching software engineering - embedded in academia. https://blog.regehr.org/archives/1569

Revelle, W. (2020). How To: Use the psych package for Factor Analysis and data reduction. https://cran.r-project. org/web/packages/psychTools/vignettes/factor.pdf

RStudio. (2019). RStudio. https://rstudio.com

Sair, S. A., \& Danish, R. (2018). Effect of performance expectancy and effort expectancy on the mobile commerce adoption intention through personal innovativeness among Pakistani consumers. Pakistan Journal of Commerce and Social Science, 12(2), 501-520. https://www.researchgate.net/publication/327702133_Effect_of_ Performance_Expectancy_and_Effort_Expectancy_on_the_Mobile_Commerce_Adoption_Intention_through_ Personal_Innovativeness_among_Pakistani_Consumers 
Saleh, A., \& Bista, K. (2017). Examining factors impacting online survey response rates in educational research: Perceptions of graduate students. Journal of Multidisciplinary Evaluation, 13(29), 63-74. https://journals.sfu. ca/jmde/index.php/jmde_1/article/view/487

Schindler, L. A., Burkholder, G. J., Morad, O. A., \& Marsh, C. (2017). Computer-based technology and student engagement: A critical review of the literature. International Journal of Educational Technology in Higher Education, 14(1), 25. doi:10.1186/s41239-017-0063-0

Shweiki, E., Martin, N. D., Beekley, A. C., Jenoff, J. S., Koenig, G. J., Kaulback, K. R., \& Cohen, M. J. et al. (2015). Applying expectancy theory to residency training: Proposing opportunities to understand resident motivation and enhance residency training. Advances in Medical Education and Practice, 6, 339-346. doi:10.2147/ AMEP.S76587 PMID:25995656

SREB.org. (2016). Bridging the computer science education gap: Five actions states can take. Southern Regional Education Board (SREB). https://www.sreb.org/sites/main/files/fileattachments/cs_commission_2016_0.pdf

Stroulia, E., Bauer, K., Craig, M., Reid, K., \& Wilson, G. (2011). Teaching distributed software engineering with UCOSP: The undergraduate capstone open-source project. In Proceedings of the 2011 Community Building Workshop on Collaborative Teaching of Globally Distributed Software Development, (pp. 20-25). Waikiki, HI: Association for Computing Machinery. doi:10.1145/1984665.1984670

SurveyGizmo. (2019). Enterprise online survey software \& tools. https://www.surveygizmo.com/

Thindwa, H. P. (2015). The role of technology in improving quality of teaching in higher education: An international perspective. In Handbook of Research on Innovative Technology Integration in Higher Education (pp. 54-73). IGI Global. doi:10.4018/978-1-4666-8170-5.ch003

Thoma, R. J., Cook, J. A., McGrew, C., King, J. H., Pulsipher, D. T., Yeo, R. A., Monnig, M. A., Mayer, A., Pommy, J., \& Campbell, R. A. (2018). Convergent and discriminant validity of the ImPACT with traditional neuropsychological measures. Cogent Psychology, 5(1), 1430199. doi:10.1080/23311908.2018.1430199 PMID:32999895

Tóth-Király, I., Bõthe, B., Rigó, A., \& Orosz, G. (2017). An illustration of the exploratory structural equation modeling (ESEM) framework on the passion scale. Frontiers in Psychology, 8, 1968. Advance online publication. doi:10.3389/fpsyg.2017.01968 PMID:29163325

Unda, X. L., \& Ramos, V. (2016). Expectancy theory applied to an educational context: A longitudinal study applied in postgraduate courses. EDULEARN16 Proceedings, 4245-4254. doi:10.21125/edulearn.2016.2027

Woods, A. D., Price, T., \& Crosby, G. (2019). The impact of the student-athlete's engagement strategies on learning, development, and retention: A literary study. College Student Journal, 53(3), 285-292. https://www. questia.com/library/journal/1G1-603511046/the-impact-of-the-student-athlete-s-engagement-strategies

Xia, Y., \& Yang, Y. (2019). RMSEA, CFI, and TLI in structural equation modeling with ordered categorical data: The story they tell depends on the estimation methods. Behavior Research Methods, 51(1), 409-428. doi:10.3758/s13428-018-1055-2 PMID:29869222 


\section{APPENDIX A. TABLES 12 AND 13}

Table 12 shows the breakdown of the experiential learning activities in the introduction to software engineering course, and Table 13 shows the perception indicators.

Table 12. Experiential learning activities in the software engineering course

\begin{tabular}{|c|c|}
\hline Activity Categories & Description \\
\hline bequtation Discussen & 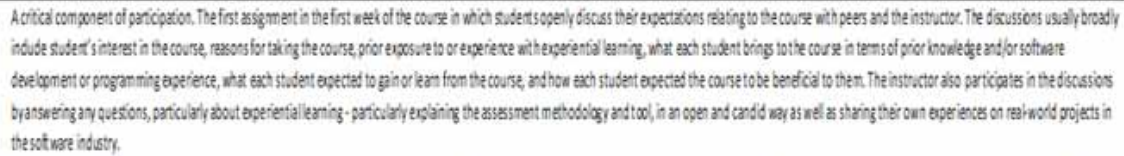 \\
\hline Tooss Btwiomentsitos: & 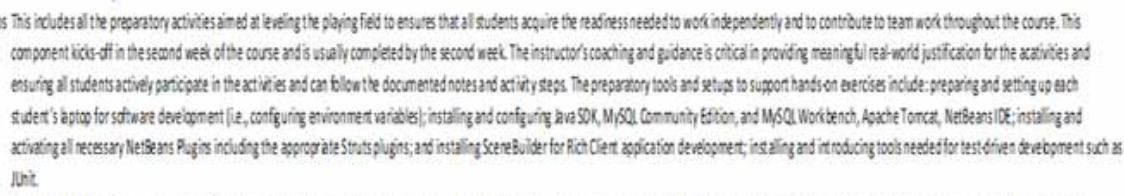 \\
\hline Hants on beroies & 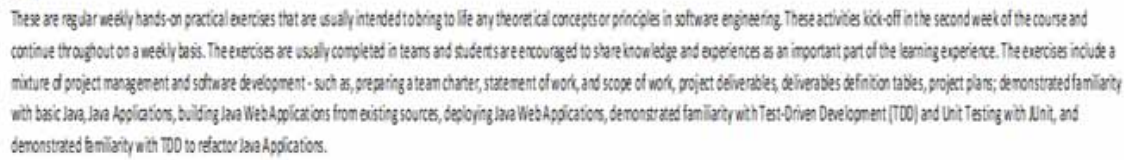 \\
\hline Delierabe Demonstution & 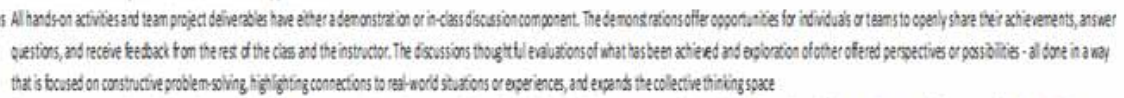 \\
\hline PreCass \& Post-Cass & 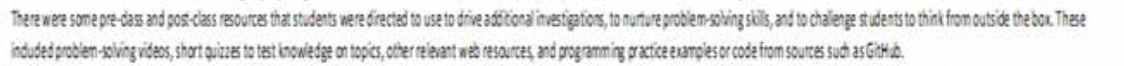 \\
\hline kiessnest & 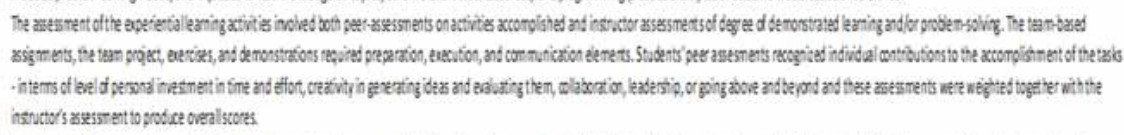 \\
\hline Unaxing & 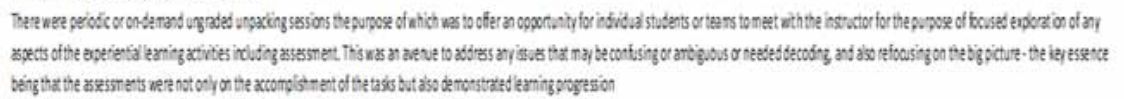 \\
\hline Teanfoieds & 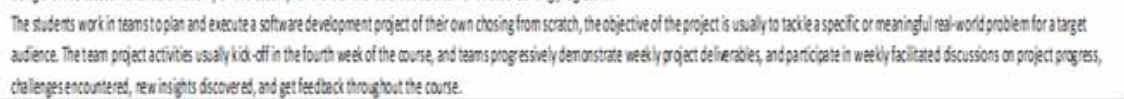 \\
\hline
\end{tabular}


Table 13. Students' perceptions indicators

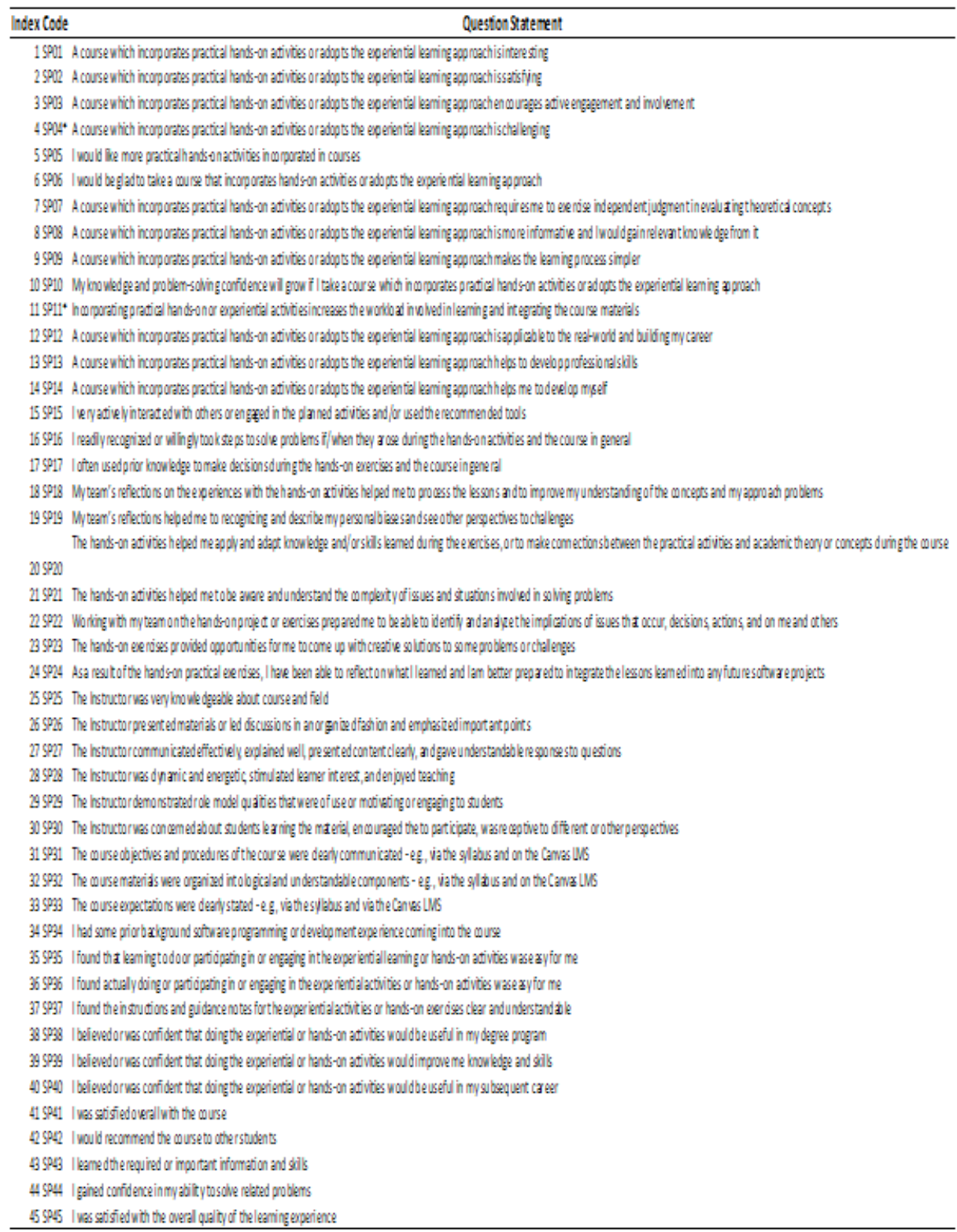

Note. Each indicator was scored using a Likert scale (1=Strongly disagree, 2=Disagree, 3=Neutral, 4=Agree, 5=Strongly Agree); * Indicator was coded 
Ferdinand Che $(P h D)$ is an Assistant Professor of Information Systems and Entrepreneurship Management. He was the Interim Associate Dean of the School of Business and Entrepreneurship at AUN from May 2015 until June 2017. He obtained his MBA from the Tuck School of Business at Dartmouth (NH, USA), his B.Sc. (Hons) and Ph.D. from the University of Kent at Canterbury (UK), and an MSc. from Oxford University (UK). He was the founder of Energy Critic Ltd, a UK boutique consulting firm based in London partnering with small and emerging companies to transform the way businesses serve customers in the technology, telecoms, logistics, and energy sectors. He also pursued other entrepreneurial interests including starting an innovative parcel delivery and logistics business in London. He has also worked for the Financial Times, GlaxoSmithKline, and other global organizations in the past, championing the use of innovation and ICTs to create value for customers in a responsible and sustainable way. His research interests are centered around harnessing the potential of technology for the benefit of society and the application of a multidisciplinary and data science approach to management problems.

Kenneth Strang $(\mathrm{PhD})$ has more than 260 mostly-sole-authored scholarly publications. He is a professor who teaches and supervises undergraduate, graduate and doctoral students across five disciplines: business administration, management information systems, marketing/consumer behavior, supply chain management and economics/statistics. Ken has a doctorate in project management (operations research), an MBA (strategic management), a BSBA (marketing), an AAS (IT) all with summa cum laude/honors plus he is an internationally licensed Project Management Professional (PMI, USA), a Certified Research Professional (IIPMR, USA), a Certified Network Administrator (Novell, USA), a Certified Supply Chain Specialist/Procurement Professional (IIPMR, USA) and a Fellow Life Management Institute with distinction (LOMA, USA). Dr. Strang has lifetime grant projects valued over $\$ 7$ million+, and he has won several honors including a Behavior Energy Climate Change Fellowship from the American Council for an Energy-Efficient Economy, the Emerald Literati award, and Duke of Edinburgh community service medal, along with several presidential citations.

Narasimha Rao Vajjhala $(P h D)$ is the Chair of the Department of Telecommunication and Network Engineering at the Faculty of Engineering and Architecture at the University of New York Tirana, Albania. He had previously served as the Chair of the Computer Science and Software Engineering departments at the School of IT and Computing at the American University of Nigeria in Yola, Nigeria. He has a doctorate in Information Systems and Technology from USA, an MBA in Information Systems from Switzerland, and a Masters' degree in Computer Applications from India. He is a senior member of Association for Computer Machinery (ACM) and Institute of Electrical and Electronics Engineers (IEEE). He is also an active member of EC-Council, Association for Information Systems (AIS) and Project Management Institute (PMI). He has over 18 years of experience in teaching mainly programming and database-related courses at both graduate and undergraduate level in Europe and Africa. He has also worked as a consultant in technology firms in Europe and has experience participating in an EU-funded project. He has supervised several undergraduate senior design projects and graduate theses. He holds several professional certifications including Project Management Professional (PMP), Certified Ethical Hacker (CEH), Microsoft Office Specialist (MOS), Certified Associate in Python Programming (PCAP), PRINCE2 Agile® Practitioner Certificate in Agile Project Management, Oracle Certified SQL Expert, Oracle Certified Associate (OCA), Microsoft Certified Trainer (MCT), Sun Certified Java Professional (SJCP), Microsoft Certified Solution Developer (MCSD), Microsoft Certified Application Developer (MCAD), IBM Cyber Security Analyst, and Cisco Certified Network Associate (CCNA). He has edited several peer-reviewed books, published monographs, peer-reviewed book chapters, refereed international conference proceedings, peer-reviewed journal articles, and review articles. He has extensive experience teaching in highly diverse cultural environments. He is fluent in English (IELTS - 8.0 on a scale of 9.0). He holds a certificate on Effective Online Tutoring from the Department of Continuing Education, Oxford University, United Kingdom and has taught several online courses for the University of Roehampton, London. He is also a certified eCommerce consultant, having completed this course from the College of Management and IT, Dublin, Ireland. 